\title{
Association of rs 10038177 and rs 1971050 Polymorphism of WDR 36 Gene with Clinical Profile in POAG Patients
}

\author{
Mehvish MALIK', Tariq KHAN', Luxmi SINGH' ${ }^{1}$ Tasleem RAZA², Syed SHAHAAN ${ }^{1}$
}

\begin{abstract}
Aim: To study WDR36 gene polymorphism (rs10038177, rs1971050) and its association with clinical parameters in patients of primary open angle glaucoma. Methods: A cross sectional study conducted on 105 cases of POAG to study its association with WDR36 gene polymorphisms (rs 10038177, rs 1971050). The study subjects underwent complete ophthalmic examination, slit lamp examination, IOP measurement by Goldmann's Applanation Tonometer, gonioscopy, fundus evaluation by 90D lens. RNFL thickness was measured using cirrus 500 OCT by Carl Zeiss. Peripheral blood samples were collected in EDTA-anticoagulant tubes, then DNA was extracted using the genomic DNA extraction and genotyped by PCR-RFLP by using (Alul) enzyme.Data analysis by SPSS, version 21.0. Chi-square and Independent sample 't'-tests used for comparison. Results: The association of genotypic expression of rs 10038177 polymorphism with different clinical variables in POAG patients, and the mean IOP (31.66 $\pm 5.88)$ and CDR $(0.72 \pm 0.15)$ for heterozygous genotype TC was significantly higher as compared to homozygous de33eeeee4( $(p<05)$ while in rs 1971050 polymorphism, Diabetic history was significantly higher in genotype TC(60\%)( $p=0.012)$ as compared to genotype TT (19.1\%). Conclusion: Our study shows that WDR 36 polymorphism (rs10038177) and (rs1971050) have an association with higher IOP and RNFL thinning which could be the underlying factors in pathogenesis and progression of POAG.
\end{abstract}

Keywords: WDR 36, POAG, polymorphism, rs10038177, rs1971050.

${ }^{1}$ Department of Ophthalmology, Era's Lucknow Medical College and Hospital, Era University, Lucknow, Uttar Pradesh, India

${ }^{2}$ Department of Biotechnology, Era's Lucknow Medical College and

Hospital, Era University, Lucknow, Uttar Pradesh, India

\section{Corresponding author:}

Luxmi SINGH, Department of Ophthalmology, Era's Lucknow Medical College and Hospital, Era University, Lucknow, Uttar Pradesh, India. E-mail: shahaan007@hotmail.com 


\section{INTRODUCTION}

Glaucoma is defined as "a progressive optic neuropathy involving characteristic structural damage to the optic nerve and resultant characteristic visual field defects" ${ }^{\text {. }}$. Primary Open Angle Glaucoma (POAG) is the most common type of glaucoma. POAG can be considered chronic, progressive optic neuropathy that is accompanied by a characteristic cupping and atrophy of the optic disc, Visual Field (VF) loss, open angles, and no obvious ocular or systemic condition ${ }^{2}$.

Age, family history, ethnicity, optic nerve damage and ocular inflammation ${ }^{3}$ are various reported risk factors associated with glaucoma. African population is at a higher risk of POAG than other ethnicities ${ }^{4}$. Ethnic differences in prevalence of POAG and projection of family history as a risk factor indicate a possible genetic link. Previous studies have shown that different adult-onset glaucoma types, including POAG fail to exhibit typical Mendelian inheritance patterns. Generally, these disorders show an age-associated manifestation with considerable heritability, however, whether genetic factors play a role is quite difficult to assess in view of the interaction of a number of genetic factors as well as effect of environmental factors.

WD repeat domain 36 gene is composed of 23 exons and is found on chromosome 5q22.1.It encodes 951 amino acid proteins with multiple $\mathrm{G}$ beta winged domain 40 (WD40) repeats. Mutations in this gene have been associated with adult-onset primary open-angle glaucoma (POAG).

In the recent years, a number of studies exploring genetic link of glaucoma have focused on SNPs in different populations. Association of SNPs in APOE, P53 and P21 genes with POAG were evaluated in Turkish and French populations ${ }^{5,6}$, MYOC gene in Pakistani population ${ }^{7}$, PLEKHA7 and COL11A1 in Chinese population ${ }^{8}$ showing varying levels of associations that still need further elaboration in different populations.

Though, the role of WDR36 in pathogenesis of glaucoma is not completely understood, however, it is hypothesized that WDR36 could have a role in T-cell activation ${ }^{9}$. T-cell responses may be involved in optic nerve degeneration ${ }^{10}$ which thereby indicates a possible link with WDR36 gene and glaucoma.

A number of WDR36 gene SNPs viz. rs11241095, rs10038177, rs17553936, rs13186912, rs13153937 and rs1971050 have been studied for their association with primary open angle glaucoma. However, the relation- ship has yet not been established and need further investigation.

Therefore, our study was intended to fill this gap in knowledge, with the purpose to evaluate the clinical presentations of POAG patients and its association with WDR36 gene polymorphism rs10038177 and rs1971050 in primary open angle glaucoma to further understand the course of the disease, favouring also the identification of risk factors, allowing multidisciplinary care and comprehensive approach to the health condition of this population.

\section{MATERIAL AND METHODS}

A cross sectional study was done at a tertiary care center of North India where the study subjects attending the ophthalmology OPD underwent a complete ophthalmic examination after taking clearance from Institutional Ethics Committee.

Patients with all other glaucoma except primary open angle glaucoma, Eye trauma, recent intraocular eye surgery or tumors, retinal changes due to preexisting ocular and extraocular lesions, Non-glaucomatous field losses, disc changes, viz. high myopia and Ischemic optic neuropathy, patients with age below 40 years and patients not willing to participate were excluded from the study.

Finally, we enrolled 105 patients with POAG with an age group of 40 to 70 years who fit our criteria for the study with their informed and written consent adhering to the tenets of the Declaration of Helsinki.

After enrolment, the details of study participants viz. age, gender, address (rural/urban) were noted. A general and systemic examination of the patients was carried out followed by recall of family and medical history of patients along with duration of disease and treatment history.

Detailed eye examination was done including best corrected visual acuity measured using Snellen's chart. This was followed by slit lamp examination, Intraocular pressure (IOP) was measured using Goldmann's Applanation Tonometer. Gonioscopy of both the eyes was also performed grading was done using Shaffer's system of grading ${ }^{11}$ Fundus evaluation was done by using 90D lens. RNFL thickness was measured using cirrus 500 OCT by Carl Zeiss. Extent and severity of glaucoma was done using Hodapp-Parrish-Anderson (HPA) Glaucoma grading scale ${ }^{12}$. The severity was defined as early, moderate and advanced/severe defect. 
Peripheral blood samples $(3 \mathrm{ml})$ of all the patients of POAG was collected in EDTA-anticoagulant tubes, and then DNA was extracted from whole blood samples using the genomic DNA extraction ${ }^{13}$.Subsequently, DNA concentration and purity was measured by UV absorption at 260 and $280 \mathrm{~nm}$.

Amplification products of WDR36 gene polymorphism (rs10038177, rs1971050) were 458bp and $238 \mathrm{bp}$ respectively. The products were digested with $10 \mu$ of restriction enzyme Alu1 and were run on $3 \%$ agarose gels.

Data Analysis: The data was analysed using Statistical Package for Social Sciences, version 21.0. Data has been represented as number and percentages. Chisquare, Independent sample ' $\mathrm{t}$ '-tests were used to compare the data.

\section{RESULTS}

The present study was carried out to study WDR36 gene polymorphism (rs10038177 and rs1971050) and its association with clinical parameters in patients with primary open angle glaucoma. The cross-sectional study was carried out in which a total of 105 glaucoma cases (210 glaucomatous eyes) were enrolled in the study. Table 1 shows the age wise distribution of study subjects:

Table 1. Age-wise and address distribution of study subjects

\begin{tabular}{|c|c|c|}
\hline $\begin{array}{c}\text { Age Group } \\
\text { (Years) }\end{array}$ & \multicolumn{2}{|c|}{ Study subjects(n=105) } \\
\hline & No- & $\%$ \\
\hline $40-49$ & 31 & 29.5 \\
\hline $50-59$ & 32 & 30.5 \\
\hline $60-69$ & 39 & 37.1 \\
\hline$>70$ & 3 & 2.9 \\
\hline $\begin{array}{l}\text { Mean Age } \pm S D \\
\text { (Range) in years }\end{array}$ & \multicolumn{2}{|c|}{$\begin{array}{c}55.41 \pm 8.56 \\
(40-70)\end{array}$} \\
\hline \multicolumn{3}{|l|}{ Address } \\
\hline Rural & 57 & 54.29 \\
\hline Urban & 48 & 45.71 \\
\hline
\end{tabular}

Table 2. Association of genotypic expression of rs10038177 polymorphism with different clinical variables $(\mathrm{N}=105)$

\begin{tabular}{|c|c|c|c|c|c|}
\hline SN & Variable & $\mathrm{CC}(n=7)$ & TC $(n=28)$ & TT $(n=70)$ & Statistical significance \\
\hline 1. & Mean Age \pm SD & $57.71 \pm 8.08$ & $57.07 \pm 8.71$ & $54.51 \pm 8.53$ & $\mathrm{~F}=1.167 ; \mathrm{p}=0.315$ \\
\hline \multirow{3}{*}{2.} & Gender & & & & \\
\hline & Male & $4(57.1 \%)$ & $20(71.4 \%)$ & $32(45.7 \%)$ & \multirow{2}{*}{$\chi^{2}=5.357 ; p=0.069$} \\
\hline & Female & $3(42.9 \%)$ & $8(28.6 \%)$ & $38(54.3 \%)$ & \\
\hline 3. & Mean $\mathrm{SBP} \pm \mathrm{SD}(\mathrm{mmHg})$ & $122.86 \pm 7.56$ & $134.29 \pm 15.74$ & $129.57 \pm 10.96$ & $\mathrm{~F}=2.894 ; \mathrm{p}=0.060$ \\
\hline 4. & Mean $\mathrm{DBP} \pm \mathrm{SD}(\mathrm{mmHg})$ & $82.86 \pm 7.56$ & $88.57 \pm 6.51$ & $87.43 \pm 7.55$ & $F=1.720 ; p=0.184$ \\
\hline 5. & Diabetic history & $1(14.3 \%)$ & $10(35.7 \%)$ & $13(18.6 \%)$ & $\chi^{2}=3.646 ; p=0.162$ \\
\hline 6. & $\begin{array}{l}\text { Family History } \\
(\mathrm{n}=31)\end{array}$ & $3(9.7 \%)$ & $14(45.2 \%)$ & $14(45.2 \%)$ & $\begin{array}{l}\chi^{2}=9.29 \\
p=0.010\end{array}$ \\
\hline \multirow{6}{*}{7.} & BCVA & & & & \\
\hline & $6 / 6-6 / 9$ & $4(28.6 \%)$ & $15(26.8 \%)$ & $53(37.9 \%)$ & \multirow{5}{*}{$\chi^{2}=11.498 ; p=0.175$} \\
\hline & $<6 / 9-6 / 18$ & $6(42.9 \%)$ & $12(21.4 \%)$ & $43(30.9 \%)$ & \\
\hline & $<6 / 18-6 / 36$ & $3(21.4 \%)$ & $13(23.2 \%)$ & $18(12.9 \%)$ & \\
\hline & $<6 / 36-6 / 60$ & 0 & $3(5.4 \%)$ & $9(6.4 \%)$ & \\
\hline & $<6 / 60$ & $1(7.1 \%)$ & $13(23.2 \%)$ & $17(12.1 \%)$ & \\
\hline 8. & Mean $\mathrm{IOP} \pm \mathrm{SD}(\mathrm{mmHg})$ & $26.61 \pm 6.91$ & $31.66 \pm 5.88$ & $27.09 \pm 6.21$ & $F=11.490 ; p<0.001$ \\
\hline 9. & Mean CDR $\pm S D$ & $0.60 \pm 0.17$ & $0.72 \pm 0.15$ & $0.61 \pm 0.15$ & $F=11.112 ; p<0.001$ \\
\hline 10. & Mean RNFL \pm SD & $77.79 \pm 18.68$ & $68.63 \pm 15.09$ & $74.08 \pm 15.06$ & $F=3.305 ; p=0.039$ \\
\hline \multirow{4}{*}{11.} & Glaucoma Grade & & & & \\
\hline & Early & $7(50.0 \%)$ & $13(23.2 \%)$ & $77(55.0 \%)$ & \multirow{3}{*}{$\chi^{2}=16.960 ; p=0.002$} \\
\hline & Moderate & $6(42.9 \%)$ & $34(60.7 \%)$ & $53(37.9 \%)$ & \\
\hline & Severe & $1(7.1 \%)$ & $9(16.1 \%)$ & $10(7.1 \%)$ & \\
\hline
\end{tabular}


Age of patients ranged from 40 to 70 years. There was a predominance of age group 60-69 years and mean age of cases was found to be $55.41 \pm 8.56$ years. Among the 105 subjects that visited our tertiary care, $54.29 \%$ belonged to rural areas while $45.71 \%$ were from urban areas.

On distribution of study subjects according to severity of glaucoma, we found that maximum number of eyes $(n=97 ; 46.2 \%)$ were diagnosed to have early glaucoma followed by moderate (44.3\%) and severe (9.5\%) respectively. Majority had glaucoma for duration of $2-5$ years $(51.4 \%)$ followed by $\leq 1$ year (23.8\%), 6-10 years $(21.9 \%)$ and $>10$ years $(2.9 \%)$ respectively. About $72.4 \%$ subjects had undertaken treatment for glaucoma while $28 \%$ subjects availed no prior treatment.
On evaluating the association of genotypic expression of rs10038177 polymorphism with different clinical variables in POAG patients, it was not found to be significantly associated with family history, IOP, CDR, RNFL and glaucoma grade. However, age, gender, systolic and diastolic blood pressure, diabetic history and best corrected visual acuity were found to be statistically insignificant. It was seen that mean IOP (31.66 \pm 5.88) and CDR (0.72 \pm 0.15$)$ for heterozygous genotype TC was significantly higher as compared to homozygous genotypes $\mathrm{CC}$ and TT and TC genotype showed significantly thinner RNFL(68.63 \pm 15.09$)(\mathrm{p}<0.05)$. Proportion of those having moderate to severe grade of glaucoma was also significantly higher in patients with TC genotype as compared to CC and TT genotypes.

Table 3. Association of genotypic expression of rs1971050 polymorphism with different clinical variables in POAG (N=105)

\begin{tabular}{|c|c|c|c|c|c|}
\hline SN & Variable & $\operatorname{CC}(n=1)$ & TC $(n=10)$ & TT (n=94) & $\begin{array}{l}\text { Statistical signif- } \\
\text { icance }\end{array}$ \\
\hline 1. & Mean Age \pm SD & 65.00 & $52.80 \pm 8.61$ & $55.59 \pm 8.55$ & $F=1.113 ; p=0.332$ \\
\hline \multirow{3}{*}{2.} & Gender & & & & \\
\hline & Male & 0 & $5(50.0 \%)$ & $51(54.3 \%)$ & \multirow{2}{*}{$\chi^{2}=1.220 ; p=0.543$} \\
\hline & Female & $1(100 \%)$ & $5(50.0 \%)$ & $43(45.7 \%)$ & \\
\hline 3. & Mean $\mathrm{SBP} \pm \mathrm{SD}(\mathrm{mmHg})$ & 130.00 & $128.00 \pm 6.33$ & $130.64 \pm 13.02$ & $\mathrm{~F}=0.199 ; \mathrm{p}=0.819$ \\
\hline 4. & Mean $\mathrm{DBP}_{ \pm} \mathrm{SD}(\mathrm{mmHg})$ & 90.00 & $84.00 \pm 5.16$ & $87.77 \pm 7.50$ & $\mathrm{~F}=1.257 ; \mathrm{p}=0.289$ \\
\hline 5. & Diabetic history & 0 & $6(60.0 \%)$ & $18(19.1 \%)$ & $\chi^{2}=8.853 ; p=0.012$ \\
\hline 6. & $\begin{array}{l}\text { Family History } \\
(\mathrm{n}=31)\end{array}$ & $0(0 \%)$ & $4(12.9 \%)$ & $27(87.1 \%)$ & $\begin{array}{l}\chi^{2}=0.975 \\
p=0.614\end{array}$ \\
\hline \multirow{6}{*}{7.} & BCVA & & & & \\
\hline & $6 / 6-6 / 9$ & $1(50.0 \%)$ & $8(40.0 \%)$ & $63(33.5 \%)$ & \multirow{5}{*}{$\chi^{2}=6.050 ; p=0.642$} \\
\hline & $<6 / 9-6 / 18$ & $1(50.0 \%)$ & $4(20.0 \%)$ & $56(29.8 \%)$ & \\
\hline & $<6 / 18-6 / 36$ & 0 & $6(30.0 \%)$ & $28(14.9 \%)$ & \\
\hline & $<6 / 36-6 / 60$ & 0 & $1(5.0 \%)$ & $11(5.9 \%)$ & \\
\hline & $<6 / 60$ & 0 & $1(5.0 \%)$ & $30(16.0 \%)$ & \\
\hline 8. & Mean $\mathrm{IOP}_{ \pm} \mathrm{SD}(\mathrm{mmHg})$ & $21.50 \pm 1.27$ & $28.25 \pm 6.89$ & $28.35 \pm 6.45$ & $F=1.108 ; p=0.332$ \\
\hline 9. & Mean CDR \pm SD & $0.50 \pm 0.14$ & $0.62 \pm 0.15$ & $0.65 \pm 0.16$ & $\mathrm{~F}=1.167 ; \mathrm{p}=0.313$ \\
\hline 10. & Mean RNFL \pm SD & $75.00 \pm 14.14$ & $78.70 \pm 17.22$ & $72.23 \pm 15.26$ & $F=1.606 ; p=0.203$ \\
\hline \multirow{4}{*}{11.} & Glaucoma Grade & & & & \\
\hline & Early & $2(100 \%)$ & $9(45.0 \%)$ & $86(45.7 \%)$ & \multirow{3}{*}{$\chi^{2}=5.031 ; p=0.284$} \\
\hline & Moderate & 0 & $11(55.0 \%)$ & $82(43.6 \%)$ & \\
\hline & Severe & 0 & 0 & $20(10.6 \%)$ & \\
\hline
\end{tabular}

In rs1971050 polymorphism, we found that Diabetic history was found to be significantly higher in heterozygous genotype $\mathrm{TC}(60 \%)(\mathrm{p}=0.012)$ as compared to homozygous genotype TT (19.1\%). All other clinical variables were found to be statistically insignificant.

\section{DISCUSSION}

A genetic link to glaucoma has been indicated by the family history of glaucoma. Moreover, congenital glaucoma, juvenile glaucoma and adult-open angle glaucoma have been indicated to have a hereditary trend ${ }^{14}$. 
These hereditary trends have led to research for the genetic links of glaucoma. Establishment of these links and identification of responsible genes is essential not only from the point of view of identifying the risk of glaucoma but also for understanding the underlying pathogenic mechanisms responsible for glaucoma. Among different types of glaucoma, primary open angle glaucoma (POAG) was found to be most common $^{15}$. Genome-wide association studies (GWAS) have identified a cluster of candidate gene locations associated with POAG. Among these, three candidate genes, viz. myocillin (MYOC), optineurin (OPTN) and WD repeat-domain 36 (WDR36) hold an important place and have been widely reported to have an association with POAG.

In this study, we have focused on identification of two SNPs rs1971050 and rs10038177 in context with clinical profile of primary open angle glaucoma.

For this purpose, a cross sectional study was performed in which a total of 105 glaucoma patients (210 glaucomatous eyes) were enrolled. Age of patients ranged from 40 to 70 years with predominance of age group 60-69 years with a predominance of the total number of males (53.3\%) (Table 1).This finding was similar to The Framingham Eye Study ${ }^{16}$ and The Barbados Eye Study ${ }^{17}$ who found that men had a significantly higher prevalence of POAG than women.

In our study, the study subjects had significantly higher systolic and diastolic blood pressure for both WDR36 gene SNPs viz. rs10038177 (Table 2) and rs1971050 (Table 3) with both SBP $(130.64 \pm 13.02 \mathrm{~mm}$ $\mathrm{hg})$ and $\mathrm{DBP}(87.77 \pm 7.50 \mathrm{~mm} \mathrm{Hg})$ being more statistically significant for rs1971050 gene polymorphism. Link between blood pressure and glaucoma is well established $^{18}$.

Diabetic history was found to be significantly lower in study subjects with association of rs 10038177 $(\mathrm{p}=0.162)$ (Table 2), while association of rs1971050 with a positive diabetic history(19\%) was found to be statistically significant $(\mathrm{p}=0.012)$ (Table 3 ). The positive relationship between diabetic history and POAG is well documented in national ${ }^{19}$ as well as international studies ${ }^{20}$. Diabetic patients are also at an increased risk of glaucoma and retinopathy. Owing to these increased risks of ocular problems, patients visiting the diabetic clinic of our facility are often referred to our department for routine evaluation. Diabetes, like POAG is a disorder that affects middle aged and elderly too often. As such, inclusion of diabetic or hypertensive patients was not ruled out in the study.
We also found that expression of rs10038177 was significantly associated with family history of glaucoma (Table 2). It has been found that first-degree relatives of patients with POAG have a risk 10 times greater of having the disease than people who have no family history ${ }^{21}$. This could help in tracing whether the family history of glaucoma could be linked with the candidate SNPs being studied.

Study subjects had a significantly poor visual acuity, higher IOP and CDR which could be attributed to the glaucomatous status of the study subjects. Mean IOP was significantly higher in rs10038177(Table 2) as compared to rs1971050 (Table 3).This is in contrast to the finding in a study by Taher et al. ${ }^{22}$, where the results of study of WDR36 gene polymorphisms rs 10038177 and $r$ s 1971050 showed no significant differences in intra- ocular pressure (IOP).

We also found heterozygous genotype TC to be associated with significantly higher systolic blood pressure, IOP, CDR, lower RNFL and higher grades of glaucoma (Table 2,3). These findings depict the possible role of this genotype in the pathogenesis and progression of glaucoma.

It must be understood that while glaucoma could have a genetic link but it also has different non-genetic factors such as lifestyle, environmental risk factors too which also play a role in pathogenesis and progression of glaucoma. The genetic link of glaucoma is still being explored and the present study is one of the contributory studies in that direction. Further studies on a larger sample size in multiple ethnicities and with inclusion of other possible candidate genes/SNPs are recommended in order to unravel this relationship further.

\section{CONCLUSION}

Our study shows that WDR 36 polymorphism (rs10038177) and (rs1971050) could have an association with higher intraocular pressure and retinal nerve fiber layer thinning which could be the underlying factors in the pathogenesis of POAG and and WDR36 may be an important factor in progression of POAG. As early diagnosis is critical for successful treatment of glaucoma, defining the genetic basis of hereditary forms of glaucoma and it's association with the clinical parameters of POAG is an important step towards a pre-symptomatic screening of people at risk. However, given insufficient present knowledge of the functional mechanisms involving this polymorphism, such find- 
ings cannot explain the pathogenesis of glaucoma at this time. Further studies with a larger sample size and inclusion of more variables could help assess the functional impact of these polymorphisms on the course of the disease.

Compliance with ethics requirements: The authors declare no conflict of interest regarding this article. The authors declare that all the procedures and experiments of this study respect the ethical standards in the Helsinki Declaration of 1975, as revised in 2008(5), as well as the national law. Informed consent was obtained from all the patients included in the study.

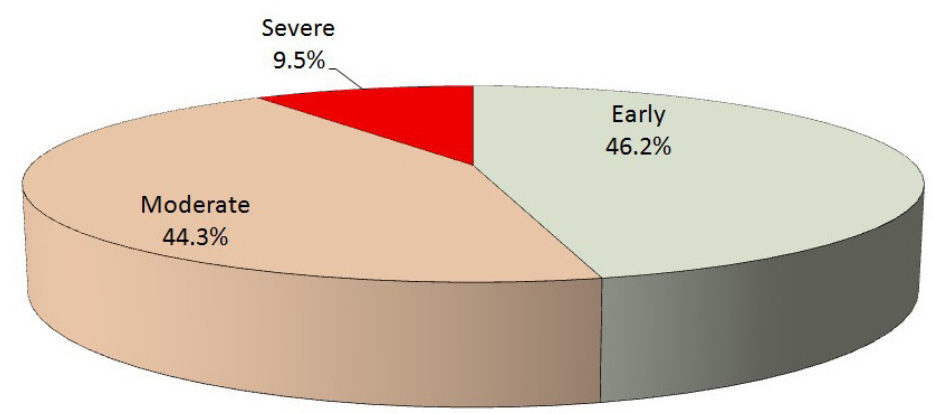

Figure 1. Distribution of study subjects according to severity of glaucoma

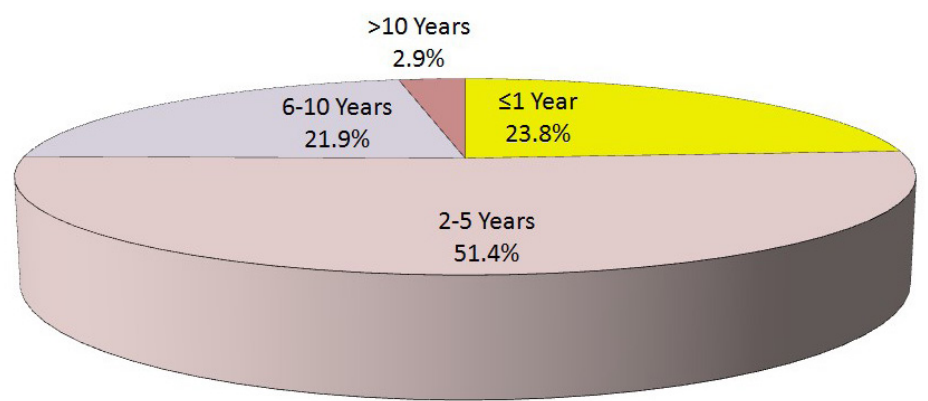

Figure 2. Distribution of study subjects according to duration of glaucoma

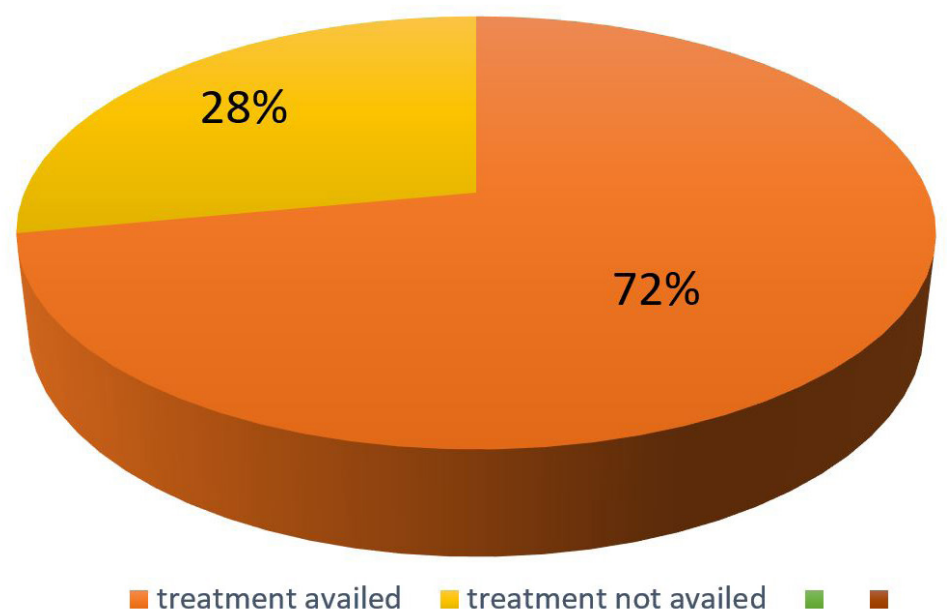

Figure 3. Distribution of study subjects according to treatment availed 


\section{References}

1. Kroese M, Burton H, Vardy S, Rimmer T, McCarter D. Prevalence of primary open angle glaucoma in general ophthalmic practice in the United Kingdom. Br J Ophthalmol. 2002;86(9):978-80.

2. Stamper RL, Liberman MF, Becker DMV. Shaffer's Diagnosis and Therapy of the Glaucomas.

3. Bodh SA, Kumar V, Raina UK, Ghosh B, Thakar M. Inflammatory glaucoma. Oman J Ophthalmol. 2011;4(1):3-9.

4. Cook C, Foster P. Epidemiology of glaucoma: what's new? Can J Ophthalmol. 2012;47(3):223-6.

5. Saglar E, Yucel D, Bozkurt B, Ozgul RK, Irkec M, Ogus A. Association of polymorphisms in APOE, p53, and p21 with primary open-angle glaucoma in Turkish patients. Mol Vis. 2009;15:1270-6.

6. Copin B, Brézin AP, Valtot F, Dascotte J-C, Béchetoille A, Garchon $\mathrm{H}$-J. Apolipoprotein E-promoter single-nucleotide polymorphisms affect the phenotype of primary open-angle glaucoma and demonstrate interaction with the myocilin gene. Am J Hum Genet. 2002;70(6):1575-81.

7. Nazir S, Mukhtar M, Shahnawaz M, Farooqi S, Fatima N, Mehmood $\mathrm{R}$, et al. A novel single nucleotide polymorphism in exon 3 of MYOC enhances the risk of glaucoma. PLoS One. 2018;13(4):e0195157.

8. Wan Y, Li S, Gao Y, Tang L, Cao W, Sun X. COL11A1 polymorphisms are associated with primary angle-closure glaucoma severity. J Ophthalmol. 2019;2019:2604386.

9. Mao M, Biery MC, Kobayashi SV, Ward T, Schimmack G, Burchard $J$, et al. T lymphocyte activation gene identification by coregulated expression on DNA microarrays. Genomics. 2004;83(6):989-99.

10. Bakalash S, Ben-Shlomo G, Aloni E, Shaked I, Wheeler L, Ofri R, et al. T-cell-based vaccination for morphological and functional neuroprotection in a rat model of chronically elevated intraocular pressure. J Mol Med. 2005;83(11):904-16.

11. Allingham RR, Damji KF, Freedman SF, Moroi SE, Rhee DJ, Shields MB (2012). Shields Textbook of Glaucoma (6th ed.). St.Paul, MN : LWW .
12. Evans J. Causes of blindness and partial sight in England and Wales 1990-1991. London: HMSO, 1995;1-29

13. Permenter J, Ishwar A, Rounsavall A, Smith M, Faske J, Sailey CJ et. al. Quantitative analysis of genomic DNA degradation in whole blood under various storage conditions for molecular diagnostic testing. Mol Cell Probes. 2015;29(6):449-53.

14. Orpha.net. [cited 2021 Jan 22]. Available from: https://www.orpha.net/data/patho/Pro/en/GlaucomaHereditary-FRenPro3563

15. Tham Y-C, Li X, Wong TY, Quigley HA, Aung T, Cheng C-Y. Global prevalence of glaucoma and projections of glaucoma burden through 2040: a systematic review and meta-analysis. Ophthalmology. 2014;121(11):2081-90..

16. Kahn HA, Leibowitz HM, Ganley JP, Kini MM, Colton T, Nickerson RS, et al. The Framingham eye study: I. Outline and major prevalence findings. American journal of epidemiology. 1977;1;106(1):17-32.

17. Leske MC. Risk factors for open-angle glaucoma: The Barbados eye study-reply. Arch Ophthalmol. 1996;114(2):235.

18. He Z, Vingrys AJ, Armitage JA, Bui BV. The role of blood pressure in glaucoma: The role of blood pressure in glaucoma. Clin Exp Optom. 2011;94(2):133-49.

19. Dave A, Bali SJ, Sharma R, Khurana AK, Gupta R, Dada T. Prevalence of diabetes mellitus and hypertension among Indian glaucoma patients and evaluation of systemic therapy. Int Ophthalmol. 2013;33(5):527-32.

20. Tielsch JM, Katz J, Quigley HA, Javitt JC, Sommer A. Diabetes, intraocular pressure, and primary open-angle glaucoma in the Baltimore Eye Survey. Ophthalmology. 1995;102(1):48-53.

21. Quigley HA. Glaucoma. Lancet. 2011;377(9774):1367-77.

22. Taher AA, Mohmmad HJ, Hussain MK, Al-Talqani HM. Two Variants of WDR36 Genes on primary open angle glaucoma. EC Ophthalmology. 2016:3:352-8. 